6. Roman GC, Roman LN. Occurrence of congenital, cardiovascular, visceral, neurological and neuroophthalmological complications in late yaws: a theme for future research. Rev Infect Dis 1986;8:760-70.

7. Purcell BK, Chamberlain NR, Goldberg MS, et al. Molecular cloning and characterisation of the 15-kilodalton major immunogen of Treponema pallidum. Infect Immun 1989;57:3708-14.

8. Noordkoek GT, Wieles B, Van Der Sluis JJ, et al. Polymerase chain reaction and synthetic DNA probes: a means of distinguishing the causative agents of syphilis and yaws? Infect Immunol 1990;58:2011-3.

9. Thornberg RW, Baseman JB. Comparison of major protein antigens and protein profiles of Treponema pallidum and Treponema pertenue. Infect Immunol 1983;42:623-7.

10. Noordhoek GT, Cockayne A, Schouls LM, et al. A new attempt to distinguish serologically the subspecies of Treponema pallidum causing syphilis and yaws. J Clin Microbiol 1990;28:1600-7.

Susan Sarangapani

Larry Benjamin

Stoke Mandeville Hospital

Aylesbury, UK

Mr Larry Benjamin

Department of Ophthalmology

Stoke Mandeville Hospital

Mandeville Road

Aylesbury

Buckinghamshire HP21 8AL, UK

Tel: +44(0)1296315035

Fax: + 44 (0)1296 315037

Sir,

\section{Lipoid proteinosis: clinical features and electron microscopic study}

Lipoid proteinosis is a rare inherited (autosomal recessive) disorder characterised by infiltration of hyaline material into the skin, oral cavity and internal organs. Its usual presentation is in infancy. We report a patient who presented late in his life with this condition. We also present the light and electron microscopic pathological features of lipoid proteinosis.

\section{Case report}

A 67-year old white man was seen in the eye clinic following a referral for visual deterioration. He was found to have cataract in both eyes and arrangements were made for cataract surgery. He was also found to have nodular lesions on the lid margins (Fig. 1a). He had first presented to the eye department 10 years previously. A diagnostic biopsy carried out at that time raised a possibility of amyloidosis, but with a suggested differential diagnosis of lipoid proteinosis. His only symptom at that time was ocular irritation. He developed hoarseness of voice only a few months later. There was no family history of lipoid proteinosis and no consanguinity between his parents.

The patient was keen on a further biopsy, as there was an initial uncertainty. He underwent an uncomplicated phacoemulsification procedure for the cataract in the right eye and skin biopsy from an eyelid.
On light microscopy (Fig. 1b), the skin of the eyelid had a thin zone of normal tissue in the superficial dermis. The reticular dermis was replaced by slightly basophilic amorphous hyaline material (Fig. 1c-e); this was periodic acid-Schiff positive and diastase-resistant, stained weakly with a colloidal iron stain (for mucin), but was Alcian blue negative and stained very faintly with Congo red stain for amyloid. Occasional cells resembling fibroblasts were present within this material.

Electron microscopy confirmed the presence of widespread extracellular deposits of electron-dense material, within which were small numbers of cells (Fig. $2 a, b)$. The electron-dense material was composed of randomly arranged short straight or curved nonbranching linear filaments (Fig. 3a) around $10 \mathrm{~nm}$ (100 $\AA$ ) in diameter, some appearing in a double 'tram-line' configuration. Collagen fibrils $40-80 \mathrm{~nm}(400-800 \AA ̊)$ in diameter passed through the material, but the material did not extend between the collagen fibrils. The occasional cells within this material showed degenerative features, including cytoplasmic swelling and vacuolation (Figs. 2a, b, 3a). Many of these stromal cells contained numerous membrane-bound structures (Fig. 3b-d) resembling (and consistent with) lysosomes; many of these contained filamentous material of similar structure to the extensive extracellular filamentous material, although occasionally the filaments in the vesicles appeared slightly longer. In occasional cells, the membrane-bound vesicles appeared to have ruptured, releasing the filamentous material into the cytoplasm of the cells. Occasional apparently 'empty' (fluid-filled) vesicles were also noted, some of which also had ruptured membranes.

\section{Comment}

Our patient has the 'classical' eyelid appearance and histological features of lipoid proteinosis. The usual presentation of this rare inherited condition is in infancy and hoarseness of voice is the first presenting symptom. Our patient, however, presented first with ocular symptoms of eyelid involvement in his sixth decade and developed hoarseness later. Ten years later, he had not developed any further symptoms. The only areas which were involved in our patient were the eyelids and the soft palate, and it is possible that he has only a mild form of the disease, without significant involvement of internal organs.

The pathogenesis of this condition is unknown. Harper et al. ${ }^{1}$ questioned whether the condition is due to disturbed collagen metabolism and Olsen et al. ${ }^{2}$ subsequently demonstrated elevated $\alpha(\mathrm{IV})$ collagen mRNA levels in in vitro cultures of human fibroblasts in this condition. Bauer et al. ${ }^{3}$ proposed that lipoid proteinosis is a lysosomal storage disorder, on the basis of finding dense membrane-bound cytoplasmic inclusions on electron microscopy and observing that some fibroblasts from the same patient developed extensive intracytoplasmic vacuoles in vitro. Moy et al. ${ }^{4}$ also found (on electron microscopy) that fibroblasts from 


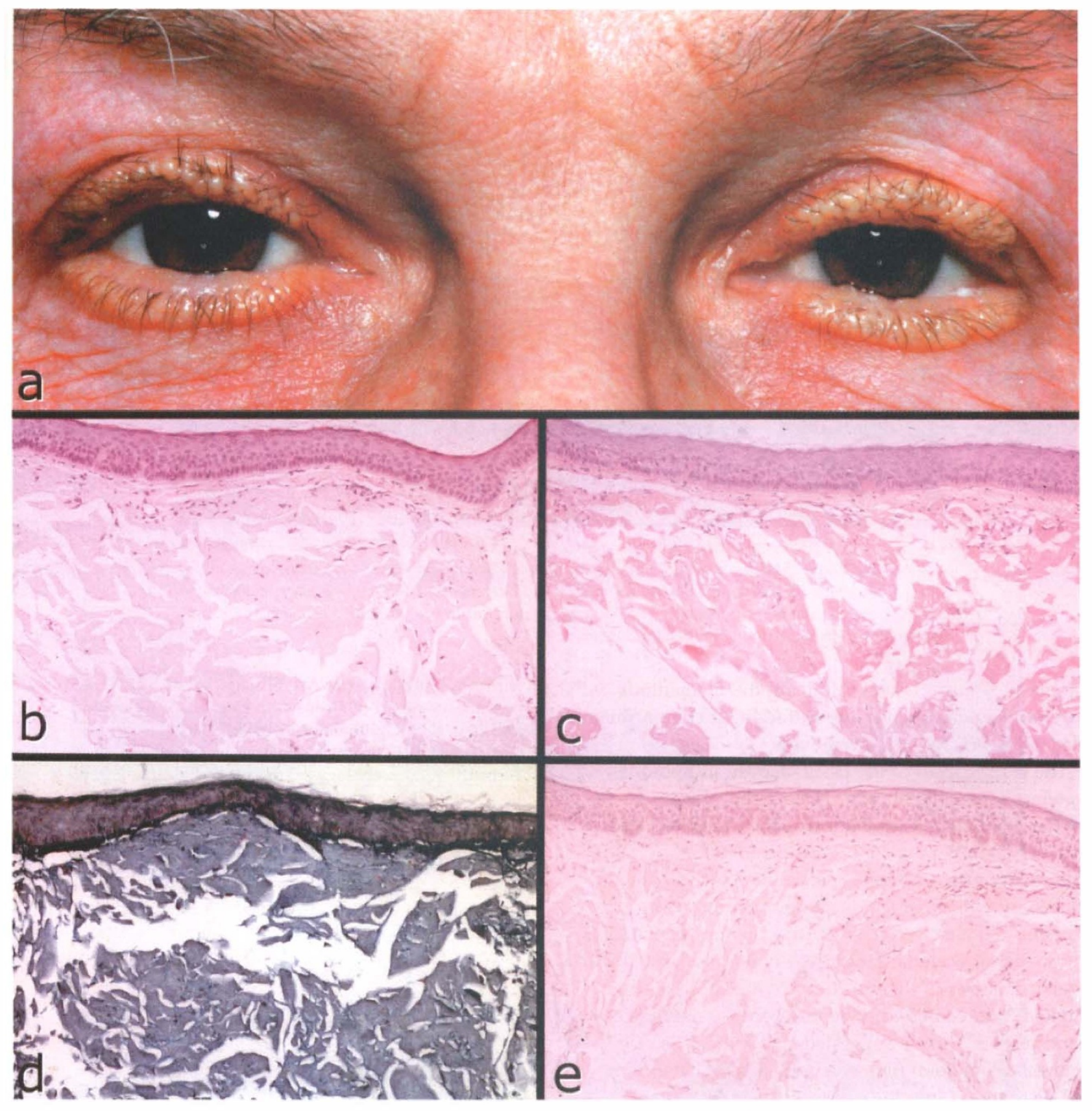

Fig. 1. (a) The patient has typical beaded waxy papules along the upper and lower eyelid margins of both eyes. On light microscopy: (b) the skin of the eyelid has a thin zone of normal tissue in the superficial dermis, the reticular dermis is replaced by slightly basophilic amorphous hyaline material, and occasional cells resembling fibroblasts are present within this material (HEE, $\times 100)$; (c) the material is periodic acid-Schiff positive and diastase resistant $(P A S, \times 100) ;(d)$ it stains weakly with a colloidal iron stain for mucin $(\times 100) ;(e)$ and stains only very faintly with Congo red stain (a negative reaction for amyloid $(\times 100)$.

a patient with lipoid proteinosis contained cytoplasmic rounded structures filled with granular electron-dense material and concluded that these were relevant to the disease process. However, these membrane-bound vesicles had not been observed in an electron microscopic study by Jenson et al. ${ }^{5}$ in 1972.

In our patient we have demonstrated electron microscopic features similar to those reported by Moy et al. ${ }^{4}$ Degenerating fibroblasts within extensive areas of extracellular filamentous material contained morphologically similar material within lysosome-like membrane-bound vesicles. In addition, however, we observed for the first time apparent rupture of these vesicles, allowing escape of this material into the cytoplasm of the cells (we also noted 'empty' vesicles which may have discharged their contents previously). If this condition was lysosomal, but with deposition of the filamentous material into the extracellular matrix, we would expect that the 'usual' mechanism would involve fusion of the lysosomal membrane with the cell membrane, prior to discharge of the contents from the cell. Our observations suggest, however, that some fibroblasts deep within extensive areas of protein deposits may be anoxic, perhaps as a result of separation from their original blood supply. Subsequent anoxic degeneration of these cells could involve rupture of the membrane-bound putative lysosomes into the 


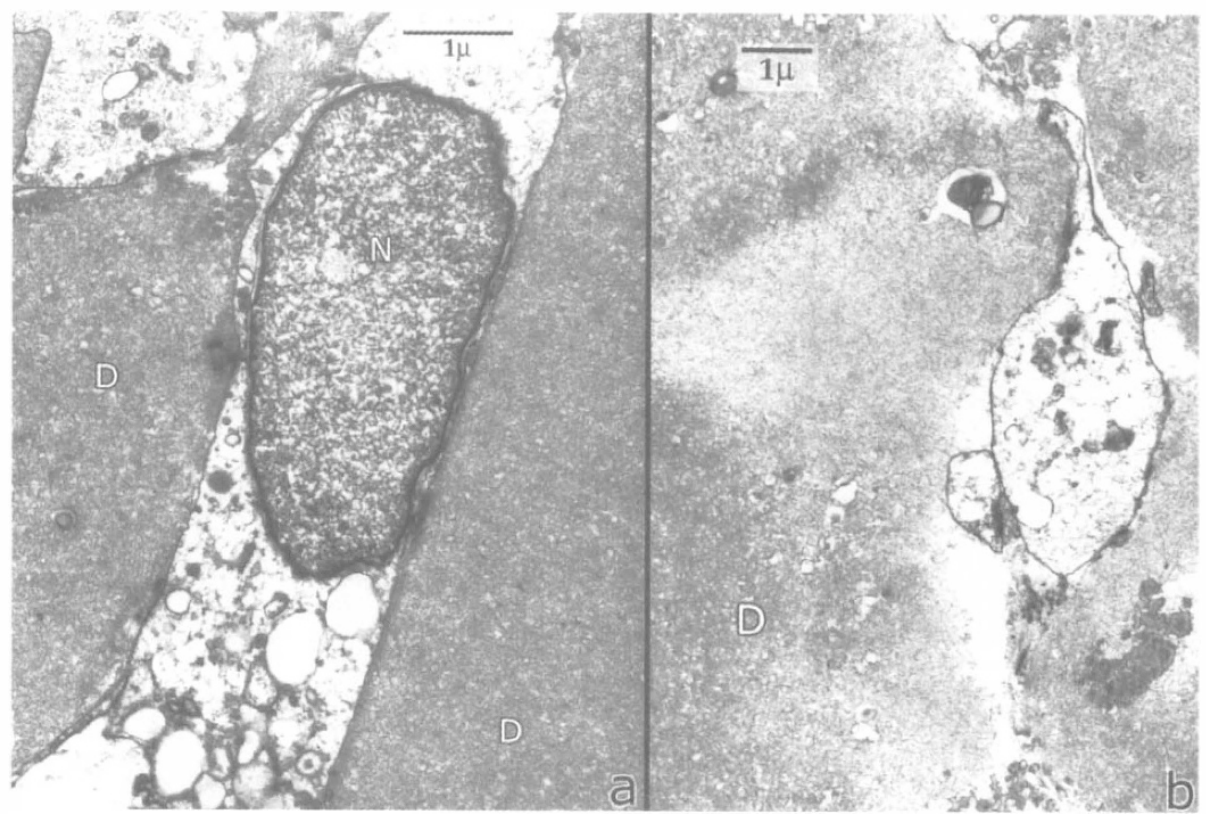

Fig. 2. Electron micrographs (scale bars represent $1 \mu \mathrm{m}$; glutaraldehyde fixation, osmium tetroxide staining). (a) Tissue from the dermis, containing widespread extracellular deposits of electron-dense material (D), within which is a cell with a central nucleus (N) and degenerative features, including cytoplasmic swelling and vacuolation. (b) Dermal tissue showing similar features to (a), with a cell showing more marked degeneration, with more vacuolated cytoplasm.

(Fig. 3 is on p.669)

cytoplasm. With eventual cell death the filamentous material would remain in the extracellular compartment after cell debris had been removed.

The exact nature of the tissue deposit in lipoid proteinosis remains unclear. Histochemical features are not those of classical amyloidosis - the Congo red stain is only very faintly pink (red when positive for amyloid), with no apple green birefringence on polarisation. Interestingly, however, at electron microscopy the filaments we observed (particularly the longer filaments within the intracellular membrane-bound vesicles) are of similar diameter (7-10 nm; 70-100 $)$ to those of amyloid $^{6}$ and could easily be mistaken for amyloid. Some authors ${ }^{7-9}$ have suggested that some cells can synthesise 'amyloid' filaments within their cytoplasm and discharge it into the extracellular matrix. One suggested mechanism is that death and disintegration of such cells leads to the release of 'amyloid' into the matrix - a mechanism not unlike that we propose for the material in at least the degenerating cells in lipoid proteinosis.

\section{References}

1. Harper JI, Duance VC, Sims TJ, Light ND. Lipoid proteinosis: an inherited disorder of collagen metabolism? Br J Dermatol 1985;113:145-51.

2. Olsen DR, Chu M-L, Uitto J. Expression of basement membrane zone genes coding for type IV procollagen and laminin by human skin fibroblasts in vitro: elevated $\alpha \mathrm{I}(\mathrm{IV})$ collagen mRNA levels in lipoid proteinosis. J Invest Dermatol 1988;90:734-8.

3. Bauer EA, Santa-Cruz DJ, Eisen AZ. Lipoid proteinosis: in vivo and in vitro evidence for a lysosomal storage disease. J Invest Dermatol 1981;76:119-25.

4. Moy LS, Moy RL, Matsuoka LY, Ohta A, Uitto J. Lipoid proteinosis: ultrastructural and biochemical studies. J Am Acad Dermatol 1987;16:1193-201.
5. Jenson AD, Khodadoust AA, Shiraz I, Emery JM. Lipoid proteinosis: report of a case with electron microscopic findings. Arch Ophthalmol 1972;88:273-7.

6. Ghadially FN. Extracellular matrix. In: Ghadially FN. Ultrastructural pathology of the cell and matrix, 2nd ed. London: Butterworth, 1982:881-947.

7. Ben-Ishay Z, Zlotnick A. The cellular origin of amyloid: electron microscopic study in a case of amyloidosis. Israel J Med Sci 1968;4:987-94.

8. Ranløv P, Wanstrup J. Electron-microscopic demonstration of intracellular amyloid in experimental mouse amyloidosis In: Mandema E, Ruinen L, Scholten JH, Cohen AS, editors. Amyloidosis. Amsterdam: Excerpta Medica, 1968:74. (Cited by Ghadially, reference 6 above.)

9. Chai CK. Reticular cell hyperplasia and amyloidosis in a line of mice with low leukocyte counts. Am J Pathol 1976;85:49-72.

\section{S. Dinakaran}

Department of Ophthalmology

Royal Hallamshire Hospital

Sheffield, UK

S.P. Desai

Department of Ophthalmology

Doncaster Royal Infirmary

Doncaster, UK

\section{I.R. Palmer}

Department of Pathology

University of Sheffield

Sheffield, UK

\section{M.A. Parsons}

Ophthalmic Sciences Unit

University of Sheffield, Sheffield, UK

\section{Mr S. Dinakaran}

Department of Ophthalmology

Royal Hallamshire Hospital

Glossop Road

Sheffield S10 2JF, UK

Tel: +44 (0)114271.1900

Fax: +44 (0)1142713747

e-mail: sdinakaran@yahoo.com 